\title{
The Causal Relationship between Bitcoin Attention and Bitcoin Returns: Evidence from the Copula-based Granger Causality Test
}

Shabbir Dastgir, Ph.D.

University of Huddersfield, Huddersfield, the United Kingdom

E-mail: s.dastgir@hud.ac.uk

Ender Demir, Ph.D.

Istanbul Medeniyet University, Istanbul, Turkey

E-mail: ender.demir@medeniyet.edu.tr

Gareth Downing, Ph.D.

University of Huddersfield, Huddersfield, the United Kingdom

E-mail: g.m.downing@hud.ac.uk

Giray Gozgor, Ph.D.

Istanbul Medeniyet University, Istanbul, Turkey

E-mail: giray.gozgor@medeniyet.edu.tr

Chi Keung Marco Lau, Ph.D.

(Corresponding Author)

University of Huddersfield, Huddersfield, the United Kingdom

E-mail: c.lau@hud.ac.uk

\section{Abstract}

This paper examines the causal relationship between Bitcoin attention (measured by the Google Trends search queries) and Bitcoin returns for the period from January 1, 2013, to December 31, 2017. For this purpose, we employ the Copula-Granger Causality in Distribution (CGCD) test. After implementing various robustness checks, we observe that there is a bi-directional causal relationship between Bitcoin attention and Bitcoin returns with the exception of the central distributions from $40 \%$ to $80 \%$. To put it differently, the bidirectional causality mainly exists in the left tail (poor performance) and the right tail (superior performance) of the distribution.

Keywords: Bitcoin; cryptocurrencies; Google trends; causality analysis; Granger causality in distribution; copula approach

JEL Classification Codes: G12; D83; C22 


\section{$\underline{\text { Highlights }}$}

$>$ We examine the causality between the Google Trends search queries and Bitcoin returns

We run the CGCD test procedure

$>$ We find a bi-directional causal relationship between the related variables with the exception of the central distributions

$>$ The bi-directional causality mainly exists in the left tail and the right tail of the distribution 


\section{Introduction}

Bitcoin (and also other crypto-currencies) have attracted the attention of various different parties such as governments, investors, and the media, mainly due to dramatic price changes, high-profit opportunities, transparency, and the potential benefits of the technology they provide. This increasing interest has also been observed in the academic literature. For instance, Nadarajah and Chu (2017) and Yonghong et al. (2018) show that Bitcoin is an inefficient market; however, Bariviera (2017) and Urquhart (2016) argue that Bitcoin might be in the process of moving towards market efficiency. Brauneis and Mestel (2018) extend the efficiency analysis to consider several crypto-currencies and find a heterogeneous pattern of efficiency. They also show that Bitcoin is the most efficient crypto-currency, and that market efficiency is positively related to market liquidity.

On the other hand, Cheah and Fry (2015), Corbet et al. (2018), and Fry and Cheah (2016) document the existence of significant bubbles in Bitcoin, Ethereum, and Ripple. Baur et al. (2018) show that Bitcoin is a speculative investment and is therefore not suitable as an alternative currency and medium of exchange; while according to Dyhrberg (2016a), Bitcoin can be used as a hedge against the stock market and the United States Dollar (USD). Likewise, Bouri et al. (2017b) show that Bitcoin has the hedge and safe haven properties at different time horizons. Dyhrberg (2016b) positions Bitcoin in between gold and the USD while combining some advantages of both. Finally, Bouri et al. (2017a) and Demir et al. (2018) show that Bitcoin has hedging capabilities against uncertainty measured by the volatility index (VIX) and the economic policy uncertainty (index), respectively.

Different from these studies, our paper aims to examine the causal relationship between Bitcoin attention (measured by the Google Trends search queries) and Bitcoin returns. The existing finance literature examines whether Google search frequencies affect stock returns and stock market volatility (see e.g., Bijl et al., 2016; Da et al., 2011; Dimpfl 
and Jank, 2016; Joseph et al., 2011). Previous studies analysing Bitcoin attention focus on Google and Wikipedia searches. For instance, Kristoufek (2013) considers the impact of the frequency of visits on the Wikipedia page as well as the impact of Google searches on Bitcoin price. The author documents a strong bi-directional relationship between the price of Bitcoin and Bitcoin searches. Using the same attention measures (Google and Wikipedia Searches), Kristoufek (2015) also finds significant co-movement between Bitcoin price and Bitcoin searches and that both engines are positively correlated in the long-run, and the relationship is most dominant at higher scales. Furthermore, Urquhart (2018) examines the impact of the attention of Bitcoin by employing Google Trends data on the price volatility, volume, and the returns of Bitcoin. The author finds that the realized volatility and the volume affect the next day's attention; while attention has no significant impact on the realized volatility and the returns of Bitcoin.

Our paper aims to enhance these findings by examining the causal relationship between Bitcoin attention (measured by Google searches for Bitcoin) and Bitcoin returns for the period from January 1, 2013, to December 31, 2017. For this purpose, we consider the Copula-Granger-causality in the Distribution (CGCD) test of Lee and Yang (2014). Doing so, we have two main contributions to the existing Bitcoin literature. First, we focus on the causal relationship in the low, the central, and the upper quantiles, since the evidence from different quantiles has been neglected by previous papers. Second, we consider six different copula functions for testing Granger-causality in both the distribution and the quantiles. Hence, this approach generates a superior forecasting performance compared to the alternative approach of quantile regression as well as avoiding quantile-crossing. Our paper finds that there is a bi-directional causal relationship between Bitcoin attention and Bitcoin returns with the exception of the central distributions from $40 \%$ to $80 \%$. To put it differently, 
the bidirectional relationship mainly exists in the left tail $(1 \%, 5 \%$, and $10 \%)$ and the right tail $(90 \%, 95 \%$, and $99 \%)$ of the distribution.

The rest of the paper is organized as follows. Section 2 presents the data, the empirical model, and the econometric methodology. Section 3 documents and discusses the empirical findings. Section 4 concludes the paper.

\section{Data, Model and Methodology}

\subsection{Data and Empirical Model}

This paper examines examine the causal relationship between Bitcoin attention (Google searches for Bitcoin) and Bitcoin returns by using weekly data for the period from January 1, 2013, to December 31, 2017. The data on Bitcoin prices are obtained from http://www.investing.com. The Google search data that represent Bitcoin attention is downloaded from the Google Trends (https://trends.google.com/trends/). Figure 1 illustrates the data on Google searches for Bitcoin and Bitcoin price.

[Insert Figure 1 around here]

Specifically, our paper estimates the following empirical models:

$$
\begin{aligned}
& \Delta \ln (\mathrm{RBC})_{\mathrm{t}}=\alpha_{0}+\alpha_{1} \ln (\mathrm{GSQ})_{\mathrm{t}}+\varepsilon_{\mathrm{t} 1} \\
& \Delta \ln (\mathrm{GSQ})_{\mathrm{t}}=\beta_{0}+\beta_{1} \ln (\mathrm{RBC})_{\mathrm{t}}+\varepsilon_{\mathrm{t} 2}
\end{aligned}
$$

Where $\Delta \ln (R B C)_{t}$ and $\Delta \ln (G S Q)_{t}$ represent the daily logarithmic returns of Bitcoin price and the logarithmic change in the Google Trends search queries (tagged "Bitcoin"), respectively. $\varepsilon_{t}$ denotes the error term in the empirical models. ${ }^{1}$

\subsection{Econometric Methodology}

Our paper applies the Copula-Granger-causality in distribution (CGCD) test that has two key advantages. Firstly, it enables us to uncover the causal relationship in the low, the central,

\footnotetext{
${ }^{1}$ We use the logarithmic change of the related variables in order to ensure the stationarity of the variables. We also implement various unit root tests and their results confirm the stationarity of the variables.
} 
and the upper quantiles. Secondly, it allows us to consider different copula functions for testing Granger-causality in both the distribution and the quantiles. Specifically, inverting the conditional copula function allows us to generate a superior forecasting performance compared to the alternative approach of quantile regression and avoids the quantile-crossing problem (Bouri et al., 2018; Lee and Yang, 2014; Shahzad et al., 2017).

At this point, we employ the CGCD method to analyse the relationship between Bitcoin returns and the Google Trends search queries. The "forecast performance" based the CGCD test of Hong and Li (2005), which is used to test the null hypothesis of $\mathrm{X}_{\mathrm{t}}$ does not Granger cause $\mathrm{Y}_{\mathrm{t}}$ in distribution: $\mathrm{H}_{0}: \mathrm{c}(\mathrm{u}, \mathrm{v})=1, \mathrm{c}(\mathrm{u}, \mathrm{v})$ is the conditional copula density function, and with $u$ and $v$ the conditional probability integral transforms of $X_{t}\left(\right.$ i.e. $\left.T V_{t}\right)$ and $Y_{t}\left(\right.$ i.e. $\left.B R_{t}\right)$. The forecasted conditional variance for $\left\{X_{t}\right\}$ and $\left\{Y_{t}\right\}, \hat{h}_{x, t+1}$ and $\hat{h}_{y, t+1}$, are computed by as such:

$$
\begin{aligned}
& \hat{h}_{x, t+1}=\hat{\beta}_{x 0}+\hat{\beta}_{x 1} x_{t}^{2}+\hat{\beta}_{x 2} \hat{h}_{t, x} \\
& \hat{h}_{y, t+1}=\hat{\beta}_{y 0}+\hat{\beta}_{y 1} y_{t}^{2}+\hat{\beta}_{y 2} \hat{h}_{t, x}
\end{aligned}
$$

We also use the empirical distribution function (EDF) to compute the cumulative distribution function (CDF) values of $\hat{u}_{t+1}$ and $\hat{v}_{t+1}$ for $\mathrm{x}_{\mathrm{t}+1}$ and $\mathrm{y}_{\mathrm{t}+1}$, while a nonparametric copula function is estimated with the EDF values $\left\{\hat{u}_{t+1}, \hat{v}_{t+1}\right\}_{t=R}^{T-1}$ using a following Quartic Kernel function:

$$
k(u)=\frac{15}{16}\left(1-u^{2}\right)^{2} I(|u| \leq 1)
$$

Our empirical analysis focuses on three distributional regions: the left tail (1\% quantile, $5 \%$ quantile, and $10 \%$ quantile), the central region (40\% quantile, median, and $60 \%$ quantile) and the right tail (90\% quantile, 95\% quantile, and 99\% quantile). The null hypothesis is that there is no copula Granger causality in the quantile. The decision as to whether to reject the null hypothesis is based on the forecast performance on the conditional quantile, $q_{\alpha}\left(Y_{t} \mid \mathcal{F}_{t}\right)$, where $\alpha$ represents the left tail probability. The conditional quantile 
$q_{\alpha}\left(Y_{t} \mid \mathcal{F}_{t}\right)$ is computed from the inverse function of following conditional distribution function (Lee and Yang, 2014):

$$
q_{\alpha}\left(Y_{t} \mid \mathcal{F}_{t}\right)=F_{Y}^{-1}\left(\alpha \mid \mathcal{F}_{t}\right)
$$

where $F_{Y}\left(Y_{t} \mid \mathcal{F}_{t}\right)$ is the predicted conditional distribution function of $\mathrm{Y}_{\mathrm{t}}$. The inverse function is to compute $q_{\alpha}\left(Y_{t} \mid \mathcal{F}_{t}\right)$ from:

$$
\int_{-\infty}^{q_{\alpha}\left(Y_{t} \mid \mathcal{F}_{t}\right)} f \gamma\left(y \mid \mathcal{F}_{t}\right) d y=\alpha
$$

where $f \gamma\left(y \mid \mathcal{F}_{t}\right)$ is the predicted conditional distribution function. We then solve the following equation and compute the quantile forecasting models $q_{\alpha}\left(Y_{t} \mid \mathcal{F}_{t}\right)$ :

$$
C_{u}\left(F_{X}\left(x_{t+1}\right), F_{Y}\left(q_{\alpha}\left(Y_{t} \mid \mathcal{F}_{t}\right)\right)=\alpha\right.
$$

The forecast performance of the quantile models $q_{\alpha}\left(Y_{t} \mid \mathcal{F}_{t}\right)$ is assessed using the six $(I=6)$ copula functions for $\mathrm{C}(\mathrm{u} ; \mathrm{v})$ based on the "check" loss function of Koenker and Bassett (1978). ${ }^{2}$ The expected check loss for a quantile forecast $q_{\alpha}\left(Y_{t} \mid \mathcal{F}_{t}\right)$ at $a$ given $\alpha$ is given by:

$$
Q(\alpha)=E\left[\alpha-I\left(Y_{t}-q_{\alpha}\left(Y_{t} \mid \mathcal{F}_{t}\right)<0\right)\right]\left(Y_{t}-q_{\alpha}\left(Y_{t} \mid \mathcal{F}_{t}\right)\right)
$$

We denote the $\mathrm{k}^{\text {th }}$ type of copula function as $\mathrm{C}_{\mathrm{k}}(\mathrm{u} ; \mathrm{v})(\mathrm{k}=1, \ldots, 1=6)$. For each copula function, we also define the corresponding quantile forecast as $q_{\alpha, k}\left(Y_{t} \mid \mathcal{F}_{t}\right)$ and its expected check loss as $Q_{k}(\alpha)$. To evaluate the difference between copula model 1 (i.e. the benchmark model of an independent copula) and model $\mathrm{k}(=2, \ldots, 6)$, we consider the corresponding check loss-differential, which is denoted by:

$$
D_{k}=Q_{1}(\alpha)-Q_{k}(\alpha)
$$

We can also estimate $D_{k}$ by the following equation:

$$
\widehat{D}_{k, p}=\widehat{Q}_{1, p}(\alpha)-\widehat{Q}_{k, p}(\alpha)
$$

\footnotetext{
${ }^{2}$ We use the Clayton, Clayton Survival, Frank, Gaussian, Gumbel, and Gumbel Survival copulas. For the detailed information about the copula approaches, refer to Lee and Yang (2014).
} 
In $\quad$ here, $\quad \hat{Q}_{k, p}(\alpha)=\frac{1}{p} \sum_{t=R}^{T-1}\left[\alpha-I\left(Y_{t}-q_{\alpha}\left(Y_{t} \mid \mathcal{F}_{t}\right)<0\right)\right]\left(Y_{t}-q_{\alpha}\left(Y_{t} \mid \mathcal{F}_{t}\right)\right), k=$ $1, \ldots, l$. The conditional quantile forecasts from using the copula distribution function $\mathrm{C}_{\mathrm{k}}(\mathrm{k}$ $=2, \ldots$ ) with the largest value $\widehat{D}_{k, p}$ will be adopted (Lee and Yang, 2014).

\section{Empirical Results}

\subsection{Results of the Initial Tests}

Firstly, we perform the structural break test of Bai and Perron (2003) to find multiple structural changes on the Bitcoin return series. The structural break date is selected in accordance with the greatest significance of the global minimizers of the sum of squared residuals (i.e. August 11, 2013). ${ }^{3}$ We consider the structural break analysis since the estimation results, which are based on the subsample, avoid instability over time, thus leading to unbiased evidence (Bai and Perron, 2003). The finding of a structural break date in August 2013 is in line with previous findings on structural breaks in the Bitcoin market (e.g. Demir et al., 2018; Kristoufek, 2015). Indeed, on August 2013, Bitcoins were accepted as "a currency or a form of money" in the United States. Specifically, Bitcoins were defined as securities, which are subject to the rules of the Federal Securities Laws. Hence, the first subsample covers January 1, 2013 to August 11, 2013, while the second subsample focuses on the period from August 12, 2013 to December 31, 2017.

Secondly, the motivation behind the use of the Copula-Granger-causality in distribution (CGCD) test was supported by the Jarque-Bera test, which shows that both timeseries are non-normally distributed. ${ }^{4}$

\footnotetext{
${ }^{3}$ We did not report the results of the test statistics of Bai and Perron (2003) to save space. The results can be reported upon request.

${ }^{4}$ Note that the Jarque-Bera statistics for the Bitcoin returns and the change of the Google Trends search are found as 63.18 and 28.98 , respectively.
} 


\subsection{Results of the Copula-Granger-causality in Distribution (CGCD) Test}

The results of the full sample and sub-sample estimations are provided in Table 1. The results of the Copula-Granger-causality in distribution test also indicate the presence of heterogeneity in the relationship between the returns of Bitcoin and the change in the Google Trends search queries. Specifically, the results show that there is no significant influence between Bitcoin returns $(R B C)$ and the change in the Google Trends search queries $(G S Q)$ at the central distribution from $40 \%$ to $80 \%$ over the whole sample period. ${ }^{5}$ However, the $p$ values reject the null hypothesis that there is no significant influence between Bitcoin returns and the change in the Google Trends search queries for the extreme quantile areas. ${ }^{6}$ Indeed, there is a bi-directional causal relationship (validity of the feedback effect) between Bitcoin returns and the Google Trends search queries at the extreme quantiles, i.e. both in the left tail $(1 \%, 5 \%$, and $10 \%)$ and the right tail $(90 \%, 95 \%$, and $99 \%)$. The results are also robust when we consider lagged (yesterday's) Bitcoin returns instead of current (today's) Bitcoin returns. Therefore, the findings suggest that the copula function enhances the quantile forecast of the relationship between Bitcoin returns and Bitcoin attention (as proxied by the Google Trends search queries), conditioning on the validity of the feedback effect in the full sample.

[Insert Table 1 around here]

In addition, we report the results for two sub-samples: i) January 1, 2013-August 11, 2013, and ii) August 12, 2013-December 31, 2017. The findings for the first sub-sample indicate that Bitcoin returns have affected the Google Trends search queries at every quantile.

\footnotetext{
${ }^{5}$ In here, we run the classical linear Granger causality test and the results indicate that there is no causal relationship between the Bitcoin returns and the changes in the Google Trends search. We did not report the results of the test statistics to save space, but the results can be reported upon request.

${ }^{6}$ Note that we report the bootstrapped p-values for testing the null hypothesis that none of the six copula models (which models Granger-causality in quantile) makes the better quantile forecast than the independent copula (which provides no Granger-causality in quantile). The p-values <0.05 indicate the rejection of the null hypothesis.
} 
This evidence is robust when we consider lagged Bitcoin returns. However, Google Trends search queries have affected Bitcoin returns at the central quantiles (from 20\% to $80 \%$ ) but there is no influence at the extreme quantiles, i.e. both in the left tail $(1 \%, 5 \%$, and $10 \%)$ and the right tail $(90 \%, 95 \%$, and 99\%). These findings provide evidence that Bitcoin returns increase Bitcoin attention and there is no extreme effect of Bitcoin attention on Bitcoin returns. The feedback effect between the related variables is valid in normal times (i.e. the central quantiles), but in extreme times, Bitcoin returns increase Bitcoin attention only over the period January 1, 2013-August 11, 2013.

According to the findings for the second sub-sample of Bitcoin returns, there is a bidirectional causal relationship (validity of the feedback effect) between Bitcoin returns and the Google Trends search queries at the extreme quantiles, i.e. both in the left tail $(1 \%, 5 \%$, and $10 \%)$ and the right tail $(90 \%, 95 \%$, and $99 \%)$. The bi-directional causal relationship also exists in some central quantiles, such as $20 \%, 30 \%, 40 \%$, and $80 \%$. These results remain robust when we consider the lagged Bitcoin returns. However, there is no significant causal relationship between the Google Trends search queries and Bitcoin returns at some central quantiles $(50 \%, 60 \%$, and 70\%) over the period August 12, 2013-December 31, 2017. These results are generally in line with the results of the whole sample. In other words, the findings of the whole sample mainly originate from the second sub-sample.

To sum up, there is a significant bi-directional causal relationship between the Google Trends search queries and Bitcoin returns with the exception of some central distributions from $40 \%$ to $80 \%$. The bidirectional relationship mainly exists in the left tail (poor performance) and the right tail (superior performance) of the distribution. We interpret these results as evidence that extreme price changes increase the attention of investors, and as the attention of investors increases the Bitcoin price is affected. These findings are in line with the previous results of Kristoufek (2013 and 2015). With a limited supply and with no 
underlying fundamentals, speculation and trends, which can be seen as a reflection of market attention, seem to significantly affect Bitcoin price changes. Therefore, investors in Bitcoin markets can benefit from Google data for their investment decisions.

\section{Conclusion}

In this paper, we examined the causal relationship between Bitcoin attention (measured by the Google Trends search queries) and Bitcoin returns for the period from January 1, 2013, to December 31, 2017. For this purpose, we employed the Copula-Granger-causality in the Distribution test of Lee and Yang (2014). After considering various initial tests and implementing robustness checks, we observe that there is a bi-directional causal relationship between Bitcoin attention and Bitcoin returns with the exception of some central distributions from $40 \%$ to $80 \%$. The bidirectional relationship mainly exists in the left tail $(1 \%, 5 \%$, and $10 \%)$ and the right tail $(90 \%, 95 \%$, and $99 \%)$ of the distribution.

Future papers on the subject may wish to focus on other cryptocurrencies to examine the relationship between their returns and the Google Trends search queries. At this stage, not only the returns, but also the price volatility of the cryptocurrencies can be analysed. Because the cryptocurrency markets have grown rapidly during the last couple of years, we should enhance our knowledge of the returns and the price volatility dynamics of the cryptocurrencies.

\section{References}

Bai, J., \& Perron, P. (2003). Computation and analysis of multiple structural change models. Journal of Applied Econometrics, 18 (1), 1-22.

Bariviera, A.F. (2017). The inefficiency of Bitcoin revisited: A dynamic approach. Economics Letters, 161, 1-4. 
Baur, D.G., Hong, K., \& Lee, A.D. (2018). Bitcoin: Medium of exchange or speculative assets? Journal of International Financial Markets, Institutions and Money, forthcoming, doi: 10.1016/j.intfin.2017.12.004.

Bijl, L., Kringhaug, G., Molnar, P., \& Sandvik, E. (2016). Google searches and stock returns. International Review of Financial Analysis, 45, 150-156.

Bouri, E., Gupta, R., Tiwari, A.K., \& Roubaud, D. (2017a). Does Bitcoin hedge global uncertainty? Evidence from wavelet-based quantile-in-quantile regressions. Finance Research Letters, 23, 87-95.

Bouri, E., Gupta, R., Lau, C.K.M., Roubaud, D., \& Wang, S. (2018). Bitcoin and global financial stress: A copula-based approach to dependence and causality in the quantiles. The Quarterly Review of Economics and Finance, forthcoming, doi: 10.1016/j.qref.2018.04.003.

Bouri, E., Molnár, P., Azzi, G., Rouband, D., \& Hagfors, L.I. (2017b). On the hedge and safe haven properties of Bitcoin: Is it really more than a diversifier? Finance Research Letters, 20, 192-198.

Brauneis, A., \& Mestel, R. (2018). Price discovery of cryptocurrencies: Bitcoin and beyond. Economics Letters, 165, 58-61.

Cheah, E-T., \& Fry, J. (2015). Speculative bubbles in Bitcoin markets? An empirical investigation into the fundamental value of Bitcoin. Economics Letters, 130, 32-36.

Corbet, S., Lucey, B., \& Yarovaya, L. (2018). Datestamping the Bitcoin and Ethereum bubbles. Finance Research Letters, forthcoming, doi: 10.1016/j.frl.2017.12.006.

Da, Z., Engelberg, J., \& Gao, P. (2011). In search of attention. The Journal of Finance, 66 (5), 1461-1499. 
Demir, E., Gozgor, G., Lau, C.K.M., \& Vigne, S.A. (2018). Does economic policy uncertainty predict the Bitcoin returns? An empirical investigation. Finance Research Letters, forthcoming, doi: 10.1016/j.frl.2018.01.005.

Dimpfl, T., \& Jank, S. (2016). Can internet search queries help to predict stock market volatility? European Financial Management, 22 (2), 171-192.

Dyhrberg, A.H. (2016a). Hedging capabilities of Bitcoin. Is it the virtual gold? Finance Research Letters, 16, 139-144.

Dyhrberg, A.H. (2016b). Bitcoin, gold and the dollar - A GARCH volatility analysis. Finance Research Letters, 16, 85-92.

Fry, J., \& Cheah, E-T. (2016). Negative bubbles and shocks in cryptocurrency markets. International Review of Financial Analysis, 47, 343-352.

Hong, Y., \& Li, H. (2005). Nonparametric specification testing for continuous-time models with applications to term structure of interest rates. The Review of Financial Studies, $18(1), 37-84$.

Joseph, K., Wintoki, M.B., \& Zhang, Z. (2011). Forecasting abnormal stock returns and trading volume using investor sentiment: Evidence from online search. International Journal of Forecasting, 27 (4), 1116-1127.

Koenker, R., \& Bassett Jr, G. (1978). Regression quantiles. Econometrica, 46 (1), 33-50.

Kristoufek, L. (2013). BitCoin meets Google trends and Wikipedia: Quantifying the relationship between phenomena of the internet era. Scientific Reports 3, 1-7, Article Number: 3415.

Kristoufek, L. (2015). What are the main drivers of the Bitcoin price? Evidence from Wavelet coherence analysis. PLoS One, 10 (4), 1-15.

Lee, T-H., \& Yang, W. (2014). Granger-causality in quantiles between financial markets: Using copula approach. International Review of Financial Analysis, 33, 70-78. 
Nadarajah, S., \& Chu, J. (2017). On the inefficiency of Bitcoin. Economics Letters, 150, 69.

Shahzad, S.J.H., Raza, N., Shahbaz, M., \& Ali, A. (2017). Dependence of stock markets with gold and bonds under bullish and bearish market states. Resources Policy, 52, $308-319$.

Urquhart, A. (2016). The inefficiency of Bitcoin. Economics Letters, 148, 80-82.

Urquhart, A. (2018). What causes the attention of Bitcoin? Economics Letters, 166, 40-44.

Yonghong, J., He, N., \& Weihua, R. (2018). Time-varying long-term memory in Bitcoin market. Finance Research Letters, forthcoming, doi: 10.1016/j.frl.2017.12.009. 
Figure 1.

Google Searches for Bitcoin (Index from 0 to 100) and Bitcoin Price (USD)

(January 1, 2013-December 31, 2017)

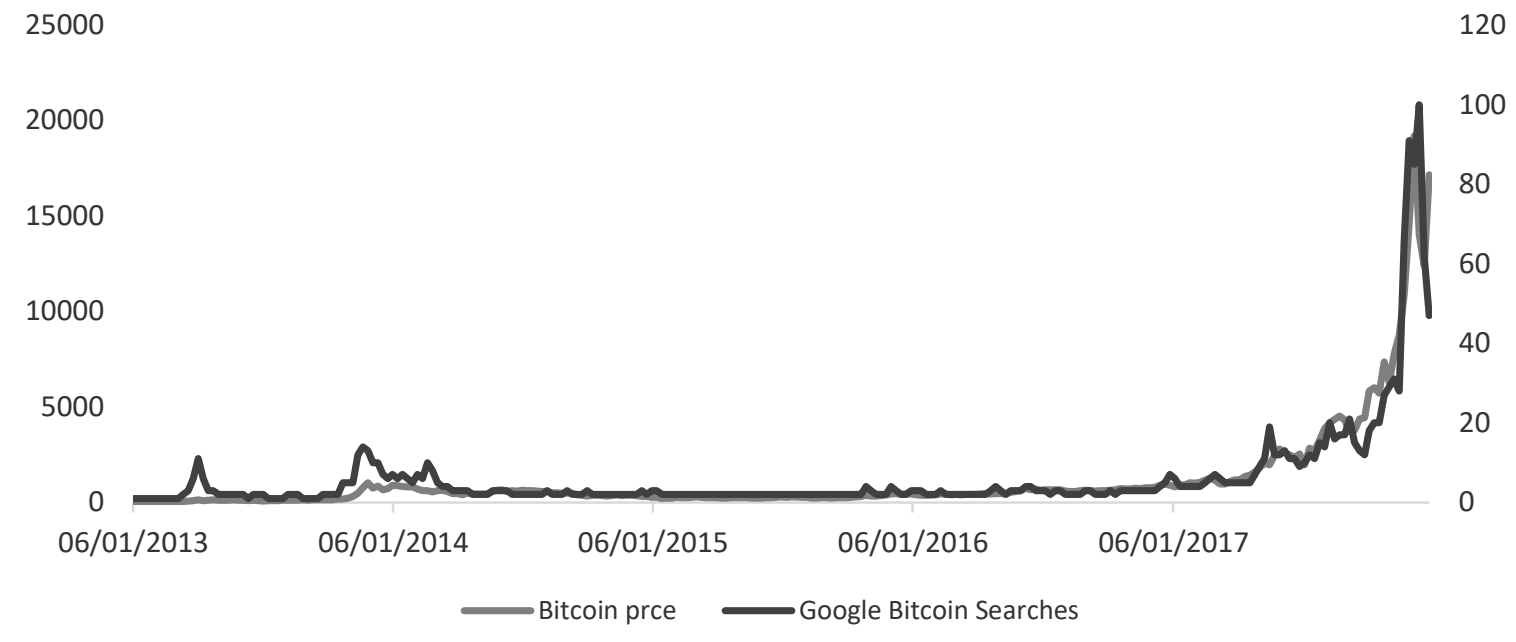


Table 1.

Results of the Copula-Granger-causality in Distribution (CGCD) Test

\begin{tabular}{|c|c|c|c|c|c|c|c|c|c|c|c|c|c|}
\hline 2013/1/1-2017/12/31 & $1 \%$ & $5 \%$ & $10 \%$ & $20 \%$ & $30 \%$ & $40 \%$ & $50 \%$ & $60 \%$ & $70 \%$ & $80 \%$ & $90 \%$ & $95 \%$ & $99 \%$ \\
\hline (RBC does not causes GSQ) & 0.0026 & 0.0132 & 0.0264 & 0.0528 & 0.0793 & 0.1057 & 0.1321 & 0.1586 & 0.1770 & 0.1448 & 0.0367 & 0.0073 & 0.0000 \\
\hline (GSQ does not causes RBC) & 0.0000 & 0.0000 & 0.0000 & 0.0000 & 0.0129 & 0.1191 & 0.2461 & 0.6052 & 0.0591 & 0.0667 & 0.0000 & 0.0000 & 0.0000 \\
\hline (RBC (-1) does not causes GSQ) & 0.0000 & 0.0000 & 0.0000 & 0.0000 & 0.0037 & 0.2112 & 0.0579 & 0.1781 & 0.1479 & 0.4912 & 0.0018 & 0.0000 & 0.0000 \\
\hline 2013/1/1-2013/8/11 & $1 \%$ & $5 \%$ & $10 \%$ & $20 \%$ & $30 \%$ & $40 \%$ & $50 \%$ & $60 \%$ & $70 \%$ & $80 \%$ & $90 \%$ & $95 \%$ & $99 \%$ \\
\hline (RBC does not causes GSQ) & 0.0000 & 0.0000 & 0.0043 & 0.0034 & 0.0000 & 0.0013 & 0.0012 & 0.0457 & 0.0000 & 0.0000 & 0.0000 & 0.0000 & 0.0000 \\
\hline (GSQ does not causes RBC) & 0.1183 & 0.1185 & 0.0749 & 0.0223 & 0.0356 & 0.0453 & 0.0052 & 0.0013 & 0.0000 & 0.0000 & 0.0962 & 0.1165 & 0.1163 \\
\hline 2013/8/12-2017/12/31 & $1 \%$ & $5 \%$ & $10 \%$ & $20 \%$ & $30 \%$ & $40 \%$ & $50 \%$ & $60 \%$ & $70 \%$ & $80 \%$ & $90 \%$ & $95 \%$ & $99 \%$ \\
\hline (RBC does not causes GSQ) & 0.0000 & 0.0000 & 0.0000 & 0.0000 & 0.0000 & 0.0000 & 0.0717 & 0.1255 & 0.2738 & 0.0042 & 0.0000 & 0.0000 & 0.0000 \\
\hline (GSQ causes RBC) & 0.0024 & 0.0027 & 0.0031 & 0.0021 & 0.0065 & 0.0044 & 0.1115 & 0.5974 & 0.0987 & 0.0023 & 0.0000 & 0.0000 & 0.0000 \\
\hline (RBC (-1) does not causes GSQ) & 0.0000 & 0.0000 & 0.0000 & 0.0000 & 0.0000 & 0.0000 & 0.0716 & 0.1256 & 0.2735 & 0.0041 & 0.0000 & 0.0000 & 0.0000 \\
\hline
\end{tabular}

Notes: We compute the quantile forecasts by inverting the parametric conditional copula distribution. We use six copulas (Clayton, Clayton Survival, Frank, Gaussian, Gumbel, and Gumbel Survival copulas). The check loss functions are compared to evaluate the predictive ability of different quantile forecasting using different copula models. The benchmark quantile forecasts are computed using the independent copula so that there is no Granger-causality in quantile. We report the bootstrapped p-values for testing the null hypothesis that none of these six copula models (which models Granger-causality in quantile) makes the better quantile forecast than the independent copula (which provides no Granger-causality in quantile). The p-values of the Reality Check $(<0.05)$ indicate the rejection of the null hypothesis, indicating that there exists a copula function to model Granger-causality in quantile and makes the better quantile forecast. 